\title{
SEKALA USAHA KLANTING DAN KONTRIBUSINYA TERHADAP PENDAPATAN KELUARGA DI DESA SIDORAHAYU KECAMATAN BELITANG OKU TIMUR
}

\author{
(Catur Giyanto)
}

\begin{abstract}
The purpose of this research were to: 1. To determine the scale of industrial enterprises in the village klanting sidorahayu Belitang District of East OKU. 2. To determine the production costs and revenue from product diversification klanting Village Belitang sidorahayu District of East OKU. 3. To find out how much industry revenue klanting contribution to the family income in the village sidorahayu Belitang District of East OKU. This research has been conducted in the village sidorahayu Belitang District of East OKU. The location determination is done deliberately, with the consideration that in the village there is a household scale industrial enterprises that process cassava into klanting. The execution of the research carried out on the Moon April-May 2014. The method used in this research is survey method with sampling techniques. This study found that the scale of effort klanting Village sidorahayu District of Belitang East OKU classified as micro, because the cost of business production average - average of $R p$ 134,792,887 per year, Revenue Average - Average Rp 206,181,818 per year and the average - average revenue of $R p$ $71,388,931$ per year, The production cost of an average effort klanting $R p 374.425$ / Pp, average receipts of $R p 572727$ / Pp and average revenue - average of $R p 198.303 / P p$ and business contribution klanting to the family income in the village sidorahayu District of Belitang East OKU by $80 \%$.
\end{abstract}

Key Words : Contributions, Scale Business, Income

\section{PENDAHULUAN}

Dalam suatu ekonomi modern, sekalipun industry kecil menengah (IKM) tetap mempunyai kesempatan besar untuk berkembang jika industri tersebut membuat jenis - jenis produk yang proses produksinya tidak mempunyai ekonomis dan mengandung teknologi sederhana tanpa mengurangi kualitas produk, serta memerlukan keahlian tertentu ( yang hanya dapat di luar sistem pendidikan formal/turun temurun).

Ubi kayu merupakan (Manihot esculenta) merupakan salah satu komoditasa pertanian yang sudah banyak dikenal. Di Kabupaten OKU Timur, banyak makanan ringan khas yang menggunakan ubi kayu sebagai bahan dasar. Selain melimpah jumlahnya, ubi kayu juga merupakan tanaman yang merakyat dan dikenal dengan nama sepe

Permasalahan yang dihadapi dalam proses pembuatan klanting yaitu pengeringan. Pengeringan selama ini hanya mengandalkan sinar matahari dengan penjemuran yaitu dengan meletakkan adonan klanting yang sudah dibentuk pada widhig (nampan yang terbuat dari bambu). Proses penjemuran klanting memerlukan waktu 79 jam sebelum dilakukan penggorengan. Penggunaan metode konvensional menyebabkan produksi klanting tidak optimal, terlebih apabila cuaca mendung atau ketika musim hujan. Hal tersebut menyebabkan proses penjemuran terhambat dan tidak sempurna yang akan menurunkan kuantitas produksi klanting.
Industri klanting adalah jenis usaha yang umumnya merupakan industri rumahan dengan investasi tidak terlalu besar dan jumlah karyawan sedikit. Namun, industri tempe telah banyak menjadi sumber penghidupan bagi rakyat kecil dan memenuhi kebutuhan produk pangan bergizi tinggi dan terjangkau bagi sebagian besar masyarakat Indonesia. Seiring dengan pertumbuhan jumlah penduduk nasional yang terus meningkat, menunjukan bahwa potensi pasar produk tempe semakin besar dan merupakan peluang untuk mengembangankan bisnis tempe. Tempe merupakan kebutuhan pokok yang dikomsumsi masyarkat OKU Timur hampir setiap hari, karena itu tempe menjadi priotas utama dalam kegiatan home industri guna untuk menambah pendapatan terhadap penghasilan keluarga, khususnya pada masyarakat desa yang kegiatannya bertani. Kabupaten OKU Timur merupakan salah satu Kabupaten, yang terletak di Provinsin Sumatera Selatan, yang kaya akan luas lahan pertanian dan hasil produksinya, baik itu tanaman pangan, perkebunan, serta perindustria, itu terlihat pada tabel di bawah ini :

Desa sidorahayu terletak di Kecamata Belitang, dengan mayoritas usaha masyarakatnya yaitu bercocok tanaman padi dan palawija, sedangkan untuk tanaman ubi kayu hampir tidak ada yang mengusahakannya, karena dinilai memakan tempat yang luas, harga jual yang rendah dan membutuhkan waktu yang lama dalam menunggu hasil. Meskipun tidak ada yang 
menanam ubi kayu, masyarakat Sidorahayu banyak memanfaatkan ubi kayu sebagai bahan baku pembuatan klanting. Menurt masyarakat Sidorahayu industri klanting di anggap sebagai usaha yang mudah dilakukan dan tidak terlalu banyak biaya produksi, serta harga jual yang tinggi dan permintaan akan kebutuhan makanan klanting diminati orang.

Selain alasan di atas, industri klanting juga mampu untuk memberikan tambahan pendapatan usahatani yang sudah ada. Dengan kemajuannya tehnologi produk klanting mengalamai perubahan atau variasi, perubahan variasi klanting bisa dilakukan dengan menambah jenis rasa, warna dan bentuk sehingga menarik konsumen untuk membeli dan member nilai tambah terhadap prodak itu sendiri. Permasalahan yang dihadapi masyarakat Sidorahayu mengenai industry kalanting yaitu kelangkaan bahan baku berupa ubi kayu. Kelangkaan bahan baku disebabkan karena kemajuan pertanian yang tadinya bertani hortikultura berubah menjadi patani kebun, sehingga lokasi untuk menanam ubi kayu semakin sedikit.

Berdasarkan latar belakang di atas, maka permasalahan yang diteliti adalah :

1. Bagaimana skala usaha industri klanting di Desa Sidorahayu Kecamatan Belitang OKU Timur.

2. Berapa biaya produksi dan pendapatan produk klanting di Desa Sidorahayu Kecamatan Belitang OKU Timur.

3. Berapa besar sumbangan pendapatan industri klanting terhadap pendapatan keluarga di Desa Sidorahayu Kecamatan Belitang OKU Timur.

\section{METODOLOGI PENELITIAN}

Penelitian ini telah dilaksanakan di Desa sidorahayu Kecamatan Belitang OKU Timur. Penentuan lokasi ini dilakukan secara sengaja, dengan pertimbangan bahwa di desa tersebut terdapat usaha industri skala rumah tangga yang mengolah ubi kayu menjadi klanting. Pelaksanaaan penelitian dilaksanakan dari Bulan April - Mei 2014. Metode yang digunakan dalam penelitian ini adalah metode survei dengan teknik sampling. Data yang dikumpulkan dalam penelitian ini data primer dan data skunder, data primer diperoleh dari pengusaha klanting dan untuk menunjang data primer digunakan data skunder yang diperoleh dari perpustakan, kantor Kecamatan Belitang yang ada kaitannya dengan penelitian ini.

\section{A. Kerangka Pemikiran}

Industri rumah tangga termasuk salah satu kegiatan usaha kecil. Badan pusat statistik mendefinisikan usaha kecil dengan ukuran tenaga, yaitu $<5$ sampai dengan dengan 10 orang yang terdiri dari (termasuk) pekerja kasar yang di bayar, pekerja pemilik dan pekerja keluarga. Suatu industri yang memiliki tenaga kerja kurang dari 5 orang diklasifikasikan sebagai industri rumah tangga. Berbeda dengan klasifikasi yang dikemukakan oleh Stanley dan morse, bahwa industri yang menyerap tenaga kerja 1 sampai 9 orang termasuk industri sedang, dan 1 industri besar menyerap tenaga kerja lebih dari 100 orang (BPS, 2003).

Sedangkan berdasarkan undang - undang no. 9/1995 tentang usaha kecil, yang dimaksud dengan usaha kecil adalah kegiatan ekonomi rakyat yang bersekala kecil dalam memenuhi kriteria kekayaan bersih atau hasil penjualan tahunan seperti kepemilikan sebagaimana diatur oleh Undang - Undang ini. Usaha kecil yang dimaksudkan disini, meliputi juga usaha kecil informal dan usaha kecil tradisional. Usaha kecil informal sebagai usaha yang belum terdaftar, belum tercatat dan belum berbadan hukum, termasuk dalam kelompok ini adalah petani penggarap, industri rumah tangga, pedagang asongan, pedagang keliling. Sedangkan yang dimaksud dengan usaha kecil tradisional adalah yang usahanya menggunakan alat produksi sederhana yang berdasarkan turun temurun biasanya dalam bidang seni dan budaya (BPS, 2003).

Komponen hasil pertanian merupakan komponen kedua dalam kegiatan agribisnis setelah komponen produksi pertanian. Banyak pula dijumpai petani yang tidak melaksanakan pengolahan hasil yang disebabkan oleh berbagai sebab padahal sesadari bahwa kegiatan pengolahan ini dianggap penting karena dapat meningkatkan nilai tambah. (Soekartawi, 2001).

Produksi adalah pengubahan dan pengolahan dari berbagai macam sember menjadi barang yang dapat dijual sesuai dengan kebutuhan. Oleh karena itu agar produksi dapat berlangsung dengan baik, perencanaan produksi merupakan hal yang penting untuk dilaksanakn seperti jenis dan jumlah barang yang akan dibuat (Soekartawi, 2001).

Kartasapoetra (2002), mengemukakan bahwa jika ditinjau dari segi ekonomis, produksi merupakan suatu pendayagunaan sumber - 
sumber yang tersedia untuk mewujudkan hasil yang terjamin kualitasnya serta terkelola dengan baik, sehingga menghasilkan komoditi yang dapat diperdagangkan.

Menurut Mubyarto (2002), mengatakan bahwa hasil yang diperoleh petani saat panen disebut produksi. Hasil akhir dari suatu proses produksi adalah produk atau output. Produksi dalam bidang pertanian dapat bervariasi disebabkan karena perbedaan kualitas atau kebutuhan manusia, dimana kemampuan berproduksi dipengaruhi oleh ketersediaan faktor - faktor produksi yang digunakan.

Menurut Mosher (2002), mengemukakan bahwa untuk mendorong petani meningkatkan produksi, diperlukan perangsang produksi berupa : a) Perbandingan harga yang menguntungkan, b) Bagi hasil yang wajar, c) Tersedianya barang dan jasa yang ingin dibeli petani dan keluarganya.

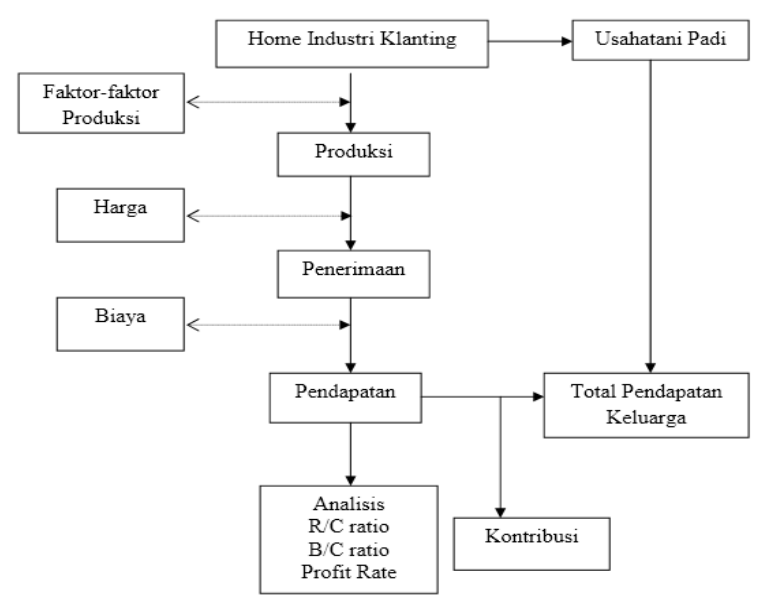

Keterangan :

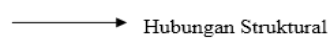

$<$ Hubungan fungsional

\section{B. Hipotesis}

Berdasarkan penelitian terdahulu dan kerangka pemikiran diagramatis, maka hipotesis dalam penelitian ini adalah :

1. Bahwa sekala usaha pada industri klanting di Desa Sidorahayu Kecamatan Belitang OKU Timur tergolong usaha mikro.

2. Bahwa penerimaan klanting lebih besar dari biaya produksi di Desa Sidorahayu Kecamatan Belitang OKU Timur

3. Bahwa industri klanting memberikan kontribusi yang tinggi terhadap keluarga di Desa Sidorahayu Kecamatan Belitang OKU Timur.

\section{Alat Analisis}

Data yang diperoleh di lapangan terlebih dahulu dikelompokkan dan kemudian diolah serta disajikan dalam bentuk tabulasi. Metode analisis yang digunakan dalam penelitian ini adalah analsis deskriftif, kualitatif dan kuantitatif. Penelitian ini hanya meneliti beberapa variabel yang dianggap paling berpengaruh, diantaranya :

1. Biaya produksi maka gunakan rumus sebagai berikut :

$$
\mathrm{TC}=\mathrm{VC}+\mathrm{FC}
$$

Dimana :

$\mathrm{TC}=$ Total Cost $/$ Total Biaya $(\mathrm{Rp})$

$\mathrm{FC}=$ Fixed Cost/Biaya Tetap $(\mathrm{Rp})$

$\mathrm{VC}=$ Variable Cost $/$ Biaya Tidak Tetap $(\mathrm{Rp})$

2. Besarnya penerimaan maka digunakan rumus sebagai berikut:

$$
\mathrm{R}=\mathrm{Op} \times \operatorname{Pr}
$$

Dimana

$\mathrm{R}=$ Revenius/Penerimaan $(\mathrm{Rp})$

$\operatorname{Pr}=$ Price/Harga $(\mathrm{Rp})$

Op $=$ Output/Hasil Produksi $(\mathrm{Kg})$

3. Besarnya pendapatan maka digunakan rumus sebagai berikut :

$$
\mathrm{I}=\mathrm{R}-\mathrm{TC}
$$

Dimana

$\mathrm{I}=$ Income/Pendapatan $(\mathrm{Rp})$

$\mathrm{R}=$ Revenius/Penerimaan $(\mathrm{Rp})$

$\mathrm{TC}=$ Total Cost/Total Biaya $(\mathrm{Rp})$

4. Tingkat keuntungan digunakan rumus sebagai berikut (Baizi, 2012). :

$$
\mathrm{R} / \mathrm{C} \text { Ratio }=\frac{\mathrm{R}}{\mathrm{C}}
$$

Keterangan :

$\mathrm{R}=$ Revenius/Penerimaan $(\mathrm{Rp})$

$\mathrm{C}=$ Cost $/$ Total Biaya $(\mathrm{Rp})$

Ratio $=$ Pembanding

Kaidah

$\mathrm{R} / \mathrm{C}>1$ Maka Usaha industri Menguntungkan.

$\mathrm{R} / \mathrm{C}=1$ Maka Usaha industri Impas.

$\mathrm{R} / \mathrm{C}<1$ Maka Usaha industri Rugi.

5. Untuk menghitung pendapatan dibagi total biaya usaha digunakan rumus sebagai berikut :

$$
\mathrm{B} / \mathrm{C} \text { Ratio }=\frac{\mathrm{B}}{\mathrm{C}}
$$

Keterangan :

$\mathrm{B}=$ Benefit/Pendapatan (Rp) 
$\mathrm{C}=\mathrm{Cos} /$ Total Biaya $(\mathrm{Rp})$

Ratio $=$ Pembanding

Kaidah

$\mathrm{B} / \mathrm{C}>1$ Maka Usaha industri Layak.

$\mathrm{B} / \mathrm{C}=1$ Maka Usaha industri Impas.

$\mathrm{B} / \mathrm{C}<1$ Maka Usaha industri Tidak Layak.

6. Untuk menghitung profit rate atau tingkat keuntungan afsolut dalam persen digunakan rumus sebagai berikut :

$$
\text { Profit Rate }=\frac{\pi}{\mathrm{TC}} \times 100 \%
$$

Keterangan :

$\pi=$ Keuntungan

$\mathrm{TC}=$ Total Cost/Total Biaya

Kaidah Analisis

- Jika Profit Rate > Maka Usaha Tersebut Fesibel.

- Jika Profit Rate < Maka Usaha Tersebut Non Fesibel.

7. Untuk menghitung kontribusi digunakan rumus sebagai berikut :

$$
\text { Kontribusi }=\frac{\text { PUI } \quad X}{\text { PUI }+ \text { PUL }} 100 \%
$$

Dimana

PUI $=$ Income/Pendapatan Dari Industri Klanting.

PUL $=$ Total Income/Total Pendapatan Keluarga

Kaidah

- Jika nilai kontribusi $0 \%$ - 33,33\% maka usaha tersebut memberikan kontribusi kecil.

- Jika nilai kontribusi 33,34\% - 66,66\% maka usaha tersebut memberikan kontribusi sedang.

- Jika nilai kontribusi 66,67\% - 99,99\% maka usaha tersebut memberikan kontribusi besar.

\section{HASIL DAN PEMBAHASAN}

\section{A. Analisis Usaha Klanting dan Usahatani}

\section{Biaya Produksi}

Biaya produksi adalah biaya yang dikeluarkan dalam suatu usaha. Usaha merupakan suatu pengolahan atau manajemen antara sumber daya alam, tenaga kerja, dan modal yang di tunjukan kepada produksi guna mencapai keuntungan yang maksimal. Guna pencapaian keuntungan yang maksimal usahatani membutuhkan biaya - biaya yang dikeluarkan dalam proses produksi, sebagai batasan maka dalam penelitian ini pengeluaran yang di maksut adalah biaya usaha industri klanting dan padi yang terdiri dari biaya tetap (fixed cost) dan biaya tidak tetap (variabel cost). Jumlah biaya produksi yang dikeluarkan oleh usaha home industri klanting dan padi berbeda - beda tergantung jumlah produksi dan skala usahanya untuk industri klanting, sedangkan untuk usahatani padi biaya produksi tergantung dari luas lahan dan sarana produksi yang dibutuhkan. Maka dari itu biaya produksi rata - rata usaha home industri klanting sebesar Rp 374,424.7/Pp, sedangkan untuk biaya produksi rata - rata usahatani padi sebesar Rp $3,696,419.2 / \mathrm{Pp}$. untuk lebih jelasnya biaya produksi usaha klanting dan usahatani padi di Desa Sidorahayu lihat pada tabel di bawah ini :

Tabel 1. Total Rata-rata Biaya Produksi Usaha Klanting dan Usaha Padi di Desa Sidorahayu.

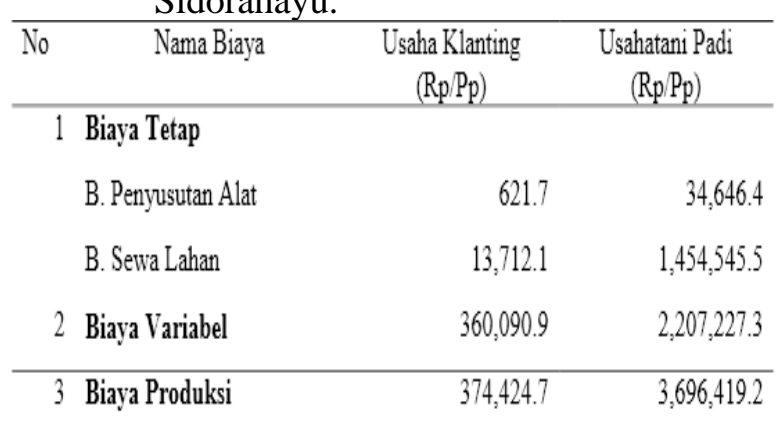

Sumber: Data Olahan, 2014.

\section{Penerimaan}

Penerimaan adalah merupakan hasil kali antara produksi yang dihasilkan dengan harga yang berlaku pada saat ini, maka penerimaan usaha home industri klanting adalah jumlah produksi klanting yang dihasilkan dalam $1 \mathrm{kali}$ proses produksi dikali dengan harga yang berlaku di pasaran/diwilayah tersebut, maka rata - rata penerimaan home industri klanting di Desa Sidorahayu sebesar $\mathrm{Rp} 572.727,3 / \mathrm{Pp}$ dengan rata - rata jumlah produksi 38,2 kg/Pp dan rata - rata harga kalanting Rp 15.000/kg , sedangkan untuk penerimaan rata - rata usahatani padi sebesar $\mathrm{Rp}$ 6.620.727,3/Pp (3 Bln), dengan rata - rata jumlah produksi $1.839,1 \mathrm{~kg} / \mathrm{ha}$, dan rata - rata harga padi sebesar Rp 3.600/ka.

Besar kecilnya penerimaan dipengaruhi dari harga produk dan jumlah produksi jika harga produk tersebut tinggi dan produksinya juga tinggi maka penerimaan juga akan besar, sebaliknya jika harga produk dan produksinya kecil maka penerimaan juga kecil. Untuk lebih jelasnya lihat pada tabel dibawah ini : 
Tabel 2. Total Rata-rata Penerimaan Usaha Klanting dan Usahatani Padi di Desa Sidorahayu.

\begin{tabular}{lrrr} 
No Jenis Usaha & $\begin{array}{r}\text { Produksi } \\
(\mathrm{Kg} P \mathrm{p})\end{array}$ & $\begin{array}{c}\text { Harga } \\
(\mathrm{Rp} / \mathrm{Kg})\end{array}$ & \multicolumn{1}{c}{$\begin{array}{l}\text { Jumlah } \\
(\mathrm{Rp} / \mathrm{Pp})\end{array}$} \\
\hline 1 Industri Klanting & 38.2 & 15,000 & $572,727.3$ \\
2 Usahatani Padi & $1,839.1$ & 3,600 & $6,620,727.3$ \\
\hline
\end{tabular}

Sumber: Data Olahan, 2014.

\section{Pendapatan}

Pendapatan adalah hasil bersih atau penerimaan bersih dari penerimaan dikurangi dengan biaya produksi. Maka dalam penelitian ini untuk menghitung pendapatan home industri klanting dan usahatani padi di Desa Sidorahayu di gunakan rumus penerimaan di kurang biaya produksi. Fungsi dari pendapatan yaitu untuk menentukan berapa besar keuntungan suatu usaha.

Berdasarkan perhitungan rata - rata pendapatan/keuntungan yang diperoleh usaha klanting sebesar Rp 198,302.6/Pp/Hari dan rata rata pendapatan usahatani padi sebesar Rp 2,924,308.2/Pp/MT. Maka dari itu usaha kalanting dan padi sawah di Desa Sidorahayu bisa dikatakan menguntungkan. Untuk lebeih jelasnya lihat pada tabel di bawah ini :

Tabel 3. Rata-rata Penerimaan, Biaya Produksi dan Pendapatan Usaha Klanting/hari dan Padi MT di Desa Sidorahayu.

\begin{tabular}{llll} 
No & \multicolumn{1}{c}{ Nama Biaya } & $\begin{array}{c}\text { Usaha kalnting } \\
(\mathrm{Rp} / \mathrm{Pp})\end{array}$ & $\begin{array}{c}\text { Usahatani Padi } \\
(\mathrm{Rp} / \mathrm{Pp})\end{array}$ \\
\hline 1 & Penerimaan & $572,727.3$ & $6,620,727.3$ \\
2 & Biaya Produksi & $374,424.7$ & $3,696,419.1$ \\
\hline 3 & Pendapatan & $198,302.6$ & $2,924,308.2$
\end{tabular}

Sumber: Data Olahan, 2014.

\section{Analisis $\mathrm{R} / \mathrm{C}$ dan $\mathrm{B} / \mathrm{C}$ Ratio}

Perhitungan R/C ratio adalah perbandingan antara total penerimaan dan total biaya yang dikeluarkan dalam proses produksi, jika nilai $\mathrm{R} / \mathrm{C}$ ratio > 1 maka usaha tersebut untung. Nilai rata-rata $\mathrm{R} / \mathrm{C}$ ratio dari usaha klanting di Desa Sidorahayu sebesar 1,5 (yang artinya setiap $\mathrm{Rp} 1$ biaya yang dikeluarkan untuk usaha klanting akan memperoleh penerimaan sebesar Rp. 1,5). Sedangkan untuk nilai rata-rata $\mathrm{R} / \mathrm{C}$ ratio dari usahatani padi di Desa Sidorahayu sebesar 1,8 (yang artinya setiap Rp 1 biaya yang dikeluarkan untuk usahatani padi akan memperoleh penerimaan sebesar Rp. 1,8). Untuk lebih jelasnya analisis $\mathrm{R} / \mathrm{C}$ ratio lihat pada tabel di bawah ini :

Tabel 4. Rata-rata Analisis R/C Ratio Usaha Klanting dan Usahatani Padi di Desa Sidorahayu.

\begin{tabular}{llclc}
\hline No & Usaha & $\begin{array}{r}\text { Penerimaan } \\
(\mathrm{Rp} / \mathrm{Pp})\end{array}$ & $\begin{array}{c}\text { Biaya produksi } \\
(\mathrm{Rp} / \mathrm{Pp})\end{array}$ & R/C Ratio \\
\hline 1 & Usaha kalnting & $572,727.3$ & $374,424.7$ & 1.5 \\
2 & Usahatani Padi & $6,620,727.3$ & $3,696,419.1$ & 1.8 \\
\hline
\end{tabular}

Sumber: Data Olahan, 2014.

Perhitungan $\mathrm{B} / \mathrm{C}$ ratio adalah perbandingan antara total pendapatan dan total biaya yang dikeluarkan dalam proses produksi, jika nilai $\mathrm{B} / \mathrm{C}$ ratio $>1$ maka usahatani tersebut layak. Nilai rata-rata $\mathrm{B} / \mathrm{C}$ ratio dari usaha klanting di Desa Sidorahayu sebesar 0,5 (yang artinya setiap $\mathrm{Rp} 1$ biaya yang dikeluarkan untuk usaha klanting akan memperoleh keuntungan $\mathrm{Rp}$. 0,5). Maka usaha klanting tidak layak untuk dikembangkan, dikarenakan terlalu besar biaya produksi yang dikeluarkan. Sedangkan untuk nilai rata-rata $\mathrm{B} / \mathrm{C}$ ratio dari usahatani Padi sebesar 0,7 ( yang artinya setiap Rp 1 biaya yang dikeluarkan untuk usahatani padi akan memperoleh keuntungan Rp. 0,7) bisa dikatan usahatani padi layak dikembangkan. Untuk lebih jelasnya lihat pada tebel dibawah ini :

Tabel 5. Rata-rata Analisis B/C Ratio Pada Usaha Klanting dan Usahatani Padi di Desa Sidorahayu.

\begin{tabular}{llcrl}
\hline No & Usaha & $\begin{array}{c}\text { Pendapatan } \\
(\mathrm{Rp} / \mathrm{Pp})\end{array}$ & $\begin{array}{c}\text { Biaya produksi } \\
(\mathrm{Rp} / \mathrm{Pp})\end{array}$ & $\mathrm{B} / \mathrm{C}$ Ratio \\
\hline 1 Usaha kalnting & $198,302.6$ & $374,424.7$ & 0.5 \\
2 & Usahatani Padi & $2,924,308.2$ & $3,696,419.1$ & 0.8
\end{tabular}

Sumber: Data Olahan, 2014.

\section{Analisis Profit Rate}

Untuk menuntukan tingkat keuntungan suatu usaha yang absolut maka digunakan rumus profit rate, dimana keuntungan di bagi dengan total biaya produksi kemudian dikali dengan 100 $\%$. Maka nilai rata - rata profit rate pada usaha klanting sebesar $53 \%$ dan $79 \%$ pada usahatani padi di Desa Sidorahayu. Jadi berdasarkan perhitungan kedua usaha tersebut memiliki keuntungan yang nyata. Untuk lebih jelasnya lihat pada tabel di bawah ini :

Tabel 6. Nilai Rata-rata Profit Rate Pada Usaha Klanting dan Usahatani Padi di Desa Sidorahayu. 


\begin{tabular}{llcccc}
\hline No & Nama Biaya & $\begin{array}{c}\text { Pendapatan } \\
(\mathrm{Rp} / \mathrm{Pp})\end{array}$ & $\begin{array}{c}\text { Biaya Produksi } \\
(\mathrm{Rp} / \mathrm{Pp})\end{array}$ & $\begin{array}{c}\text { Persentase } \\
100 \%\end{array}$ & $\begin{array}{c}\text { Profit Rate } \\
\%\end{array}$ \\
\hline 1 & Usaha Klanting & $198,302.6$ & $374,424.7$ & 100 & 53. \\
2 & Usaha Padi & $2,924,308.2$ & $3,696,419.1$ & 100 & 79
\end{tabular}

Sumber: Data Olahan, 2014.

\section{B. Analisis Kontribusi Usaha Klanting Terhadap Pendapatan Keluarga.}

Kehidupan petani tidaklah tergantung sepenuhnya dari usahatani padi sawah tetapi ada sebagian dan mungkin beberapa diantaranya memiliki kegiatan usahalain seperti industri rumah tangga. Desa Sidorahayu merupakan salah satu desa yang penduduknya mengusahakan industri klanting guna untuk menambah pendapatan usahatani padinya. Kontribusi adalah sumbangan pendapatan usaha lain terhadap pendapatan keluarga yang sudah ada. Untuk mengetahui kontribusi pendapatan usaha klanting terhadap pendapatan keluarga petani dihitung dengan membagikan pendapatan home industri klanting di bagi dengan total pendapatan petani kemudian di kali 100\%. Untuk lebih jelasnya lihat pada tabel di bawah ini :

Tabel 7. Kontribusi Usaha Klanting Terhadap Pendapatan Keluarga di Desa Sidorahayu.

\begin{tabular}{llll}
\hline No & Nama Usaha & $\begin{array}{c}\text { Jumlah Pendapatan } \\
(\mathrm{Rp} / \mathrm{Pp} / 4 \mathrm{Bln})\end{array}$ & $\begin{array}{c}\text { Persentase } \\
(\%)\end{array}$ \\
\hline 1 & Usahatani Klanting & $11,898,155.2$ & 80.3 \\
2 & Usahatani Padi & $2,924,308.2$ & 19.7 \\
\hline 3 & Total Pendapatan & $14,822,463.3$ & 100
\end{tabular}

Sumber: Data Olahan, 2014.

Tabel di atas menunjukan bahwa kontribusi pendapatan dari usaha klanting rata rata sebesar $80,3 \%$. Maka dapat disimpulkan bahwa usaha home industri kalnting di Desa Sidorahayu Kecamatan Belitang OKU Timur memberikan kontribusi yang tinggi terhadap pendapatan keluarga.

\section{Sekala Usaha Industri Klanting}

Sekala usaha secara umum adalah suatu ukuran untuk menentukan/menggolongkan sebuah usaha tersebut di katakan usaha mikro, kecil, menengah. Dalam menentukan sekala usaha tersebut bisa menggunakan jumlah modal yang digunakan, pendapatan yang di peroleh dan jumlah tenaga kerja.

a.Karekteristik Usaha Mikro

- Jenis barang/komoditi usahanya tidak selalu tetap, sewaktu-waktu dapat berganti.

- Tempat usahanya tidak selalu menetap, sewaktu-waktu dapat pindah tempat.

- Belum melakukan administrasi keuangan yg sederhana sekalipun, dan tidak memisahkan keuangan keluarga dengan keuangan usaha.

- Sumber daya manusianya (pengusahanya) belum memiliki jiwa wirausaha yang memadai.

- Tingkat pendidikan rata-rata relatif sangat rendah.

- Umumnya belum akses kepada perbankan, namun sbgn sudah akses ke lembaga keuangan non bank.

- Umumnya tidak memiliki izin usaha atau persyaratan legalitas lainnya termasuk NPWP.

b. Karakteristik Usaha Kecil

- Jenis barang/komoditi yang diusahakan umumnya sudah tetap tidak gampang berubah.

- Lokasi/tempat usaha umumnya sdh menetap tdk berpindah-pindah.

- Pada umumnya sudah melakukan administrasi keuangan walau masih sederhana, keuangan perusahaan sudah mulai dipisahkan dengan keuangan keluarga, sudah membuat neraca usaha.

- Sudah memiliki izin usaha dan persyaratan legalitas lainnya termasuk NPWP.

- Sumberdaya manusia (pengusaha) memiliki pengalaman dalam berwira usaha;

- Sebagian sdh akses ke perbankan dlm keperluan modal.

- Sebagian besar belum dapat membuat manajemen usaha dengan baik seperti business planning.

c. Karakteristik Usaha Menengah

- Umumnya memiliki manajemen dan organisasi yang lebih baik, lebih teratur bahkan lebih modern, dengan pembagian tugas yang jelas antara lain, bagian keuangan, bagian pemasaran dan bagian produksi.

- Telah melakukan manajemen keuangan dengan menerapkan sistem akuntansi dengan teratur, sehingga memudahkan untuk auditing dan penilaian atau pemeriksaan termasuk oleh perbankan. 
- Telah melakukan aturan atau pengelolaan dan organisasi perburuhan, telah ada Jamsostek, pemeliharaan kesehatan dll.

- Sudah memiliki segala persyaratan legalitas antara lain izin tetangga, izin usaha, izin tempat, NPWP, upaya pengelolaan lingkungan dll.

- Sudah akses kepada sumber-sumber pendanaan perbankan.

- Pada umumnya telah memiliki sumber daya manusia yang terlatih dan terdidik.

Tabel 8. Kriteria Usaha Mikro, Kecil, dan Menengah.

No Ukuran Usaha $\quad$ Modal $\quad$ Pendapatant thn

$\begin{array}{llll}\text { 1. } & \text { Usaha mikro } & \text { Maksimal } 50 \text { juta } & \text { Maksimal } 300 \text { juta } \\ \text { 2. Usaha Kecil } & >50 \text { juta }-500 \text { juta } & \text { Maksimal } 300 \text { juta } \\ \text { 3. } & \text { Usaha Menengah } & >500 \text { juta }-10 \text { milyar } & >2,5-50 \text { milyar }\end{array}$

Sumber: UU No.20 tahun 2008.

Berdasarkan kriteria diatas dapat di simpulkan bahwa usaha klanting di Desa Sidorahayu Kecamatan Belitang tergolong usaha mikro, di karenakan biaya produksi rata-rata sebesar Rp 374,425/Pp kemudian di kali dengan 360 hari menjadi Rp 134,792,887/Thn. Untuk penerimaan Rata-rata sebesar Rp 572.727,27/Pp kemudian di kali dengan 360 hari menjadi Rp 206.181.818/Thn. Sedangkan untuk pendapatan rata-rata usaha klanting sebesar Rp 198,303/Pp kemudian di kali dengan 360 hari menjadi Rp $71,388,931 /$ Thn. Untuk lebih jelasnya lihat pada tabel di bawah ini.

Tabel 9. Rata-rata Biaya Produksi, Penerimaan dan Pendapatan Usaha Klanting Pertahun.

\begin{tabular}{llrr}
\hline No & Nama Biaya & \multicolumn{2}{c}{ Usaha Klanting } \\
& & $(\mathrm{Rp} / \mathrm{Pp})$ & \multicolumn{1}{c}{$(\mathrm{Rp} / \mathrm{Thn})$} \\
\hline 1 Biaya Produksi & 374,425 & $134,792,887$ \\
2 Penerimaan & 572,727 & $206,181,818$ \\
3 Pendapatan & 198,303 & $71,388,931$
\end{tabular}

Sumber: Data Olahan, 2014.

\section{IV.KESIMPULAN DAN SARAN}

\section{A. Kesimpulan}

Berdasarkan hasil penelitian yang dilakukan dan dapat diambil kesimpulan :

1. Skala usaha klanting di Desa Sidorahayu Kecamatan Belitang OKU Timur tergolong usaha mikro, dikarenakan biaya produksi usaha rata - rata sebesar Rp 134,792,887/Thn, Penerimaan Rata - rata sebesar Rp 206,181,818/Thn dan rata - rata pendapatan sebesar Rp 71,388,931/Thn.

2. Biaya produksi rata-rata usaha klanting sebesar Rp 374,425/Pp, rata-rata penerimaan sebesar Rp 572.727/Pp dan pendapatan rata rata sebesar Rp 198,303/Pp

3. Kontribusi usaha klanting terhadap pendapatan keluarga di Desa Sidorahayu Kecamatan Belitang OKU Timur tergolong dalam kontribusi yang tinggi dengan nilai persentase sebesar $80 \%$.

\section{B. Saran}

Saran yang dapat diberikan peneliti adalah usaha klanting adalah usaha yang menguntungkan dan memiliki prospek yang baik sehingga layak untuk dikembangkan. Dengan semakin bertambahnya jumlah penduduk maka kebutuhan akan pangan juga bertambah, sehingga usaha klanting mampu menjadi penyedia kebutuhan pangan. Sedangkan untuk limbah ubikayi yang berupa kulit ubi bisa digunakan sebagai pupuk organik, sehingga limbah tersebut tidak mencemari lingkungan di sekitar.

\section{DAFTAR PUSTAKA}

Arikunto dan Suharsimi. 2002. Prosedur Penelitian Suatu Pendekatan Praktek. Rineka Cipta. Jakarta.

Azzaino,Z. 2006. Pengantar Tataniaga Pertanian. Fakultas Pertanian Institut Pertanian Bogor. Bogor.

Hernanto, F. 2003. Ilmu Usaha Tani. PT Bina Aksara. Jakarta.

Kartasapoetra, A.G. 2005. Management Pertanian (agribisnis). Bima Aksara. Jakarta.

Manulang. 2003. Harga Dalam Proses Produksi. Grafindo. Jakarta.

Mosher, A.T. 2002. Menggerakkan dan Membangun Pertanian. Universitas Indonesia. Jakarta.

Mubyarto. 2002. Pengantar Ilmu Pertanian. Lembaga Penelitian, Pendidikan dan Penerangan Ekonomi. jakarta.

Sjarkowi, F. dan M. Sufri. 2004. Manajemen agribisnis. CV Baldad Grafiti Press. Palembang.

Soeharjo dan Patong. 2003. Sendi - Sendi Pokok Ekonomi Usaha Tani. Departemen Ilmu - Ilmu Sosial Ekonomi Pertanian Fakultas Pertanian Bogor. Bogor. 
Soekartawi. 2005. Pengantar Agroindustri. Raja Grafindo Perseda. Jakarta.
Sudjoko. 2001. Profil Industri Kecil dan Kerajinan Rumah Tangga. BPS. Jakarta. 